\title{
Anesthetic Management of Cochlear Implant Surgery in a Patient with Alport Syndrome
}

\author{
Pavithra $\mathbf{V}^{1^{*}}$ and Monal $\mathbf{N}$ Ramani ${ }^{2}$ \\ ${ }^{1,2}$ Department of Anesthesiology, BJ Medical College, Ahmedabad, India
}

Received: October 03, 2017; Accepted: October 27, 2017, Published: November 04, 2017

*Corresponding author: Pavithra V, Resident, Department of Anesthesiology, BJ Medical College, Ahmadabad, India, Tel.: 7022044720; E-mail: drpavithrav@gmail.com

\begin{abstract}
Background: Cochlear implants are now an acceptable therapeutic option for those patients with irreversible hearing loss and deaf-mutism. The surgery is time consuming and complicated. Hence, the technique of anaesthesia plays a crucial role in success of cochlear implant surgery. Cochlear implant patients have various types of syndromes which are important from anaesthetic as well as surgical point of view. Pre-implant preparation requires objective assessment of hearing, plain X-rays of skull and a CT scan of the temporal bone. Anaesthesia is required for objective assessment of hearing in children under five years of age, to obtain X-rays of skull, Magnetic Resonance Imaging (MRI), CT scan, Brain Evoked Response Audiometry (BERA) testing and finally for cochlear implant surgery. Anaesthetic considerations include preoperative familiarisation with the patient and his family. Syndromal illnesses have specific anaesthetic significance such as presence of difficult airway or prolonged QT interval. Parental presence is highly desirable during induction of anaesthesia. Electro-surgical instruments especially monopolar ones, should not be used once the cochlear implant is in place.
\end{abstract}

Aim: To provide a standard balanced anesthetic management in a patient with Alport Syndrome with sensorineural hearing loss and post renal transplant posted for cochlear implant surgery.

Material \& Methods: The case includes an eight year old male child with post renal transplant surgery with Alport syndrome where in care has been taken to maintain adequate hemodynamic status \& renal function with efficient anesthetic administration. The technique of general anaesthesia was modified to permit use of nerve stimulators during surgery. To minimize the incidence of vertigo particularly after cochleostomy, postoperative nausea and vomiting, the patient received glycopyrrolate and fentanyl citrate intravenously prior to induction. Other agents used were, thiopentone, suxamethoniumand end-tidal 1 MAC sevofluranein 1:2 mixture of oxygen and nitrous oxide (02 and N2 0). Electro diathermy was switched off, before the cochlear device was implanted on the patient. Patient was allowed to breathe spontaneously whenever nerve stimulator was used to locate the facial nerve. Inj Ondansetron $0.1 \mathrm{mg} / \mathrm{kg}$ was used as anti-emetic agent. Postoperative pain relief was initially provided with fentanyl $1 \mu \mathrm{g} / \mathrm{kg}$ IV and later with syrup ibuprofen.

Conclusion: The study throws light upon the precautions \& preliminary methods followed in providing balanced anesthesia to the patient of Alport syndrome with renal transplant undergoing the cochlear implant surgery. Complicated patients with syndromic features have to be managed carefully in order to avoid various anesthetic complications. There was no remarkable anaesthetic or surgical complication

\section{Introduction}

Alport syndrome (progressive hereditary nephritis )is a triad of progressive renal disease, hearing loss and eye defect, its incidence being 1:5000.Mutations in a variety of gene encoding the type IV basement membrane specific collagen chainswhich are the integral component of glomerular basement membrane,cochlea and the eye is the etiologicalfactor for this syndrome.

Renal transplantation is indicated in patients of alport syndrome with end stage renal disease. Cochlear implantation in such patients with Alport Syndrome following Renal Transplantation is exceedingly rare and done in very few centers across the world.
The field of cochlear implantation has been expanding rapidly and now it is an acceptable therapeutic option for those patients with irreversible hearing loss and deafmutism. It has been hailed as one of the greatest advances in otology. Cochlear implants are extremely expensive computerised electric prostheses that partially replace the functions of the cochlea. The surgery is time consuming and is performed under general anaesthesia via a trans-mastoid approach [1]. The operative technique is complicated and necessitates preservation of functional integrity of the facial and cochlear nerve. The anaesthesiologist is an integral member of the cochlear implant team whose anaesthetic as well as communication skills are put to test. The technique of anaesthesia plays a crucial role in success of cochlear implant surgery as the anaesthesiologist has to produce conditions which facilitate use of nerve stimulators and treat troublesome post- 
operative complications such as nausea, vomiting and vertigo. This paper highlights certain important technical aspects of the surgery and our anaesthetic experience with a case of Alport syndrome undergoing cochlear implant surgery[2].

\section{Objectives}

1.To facilitate safe and effective perioperative management of cochlear implant surgery in a patient with renal and hepatic impairment.

2.To reduce the incidence of adverse outcome as it is not a routinely encountered case history.

\section{Case Report}

\section{Brief History}

An eight year old male patient, weighing $19 \mathrm{~kg}$ with a diagnosis of Alport syndrome with bilateral sensorineural hearing loss with renal transplantation with hepatitis $\mathrm{C}$ infection.

Patient presented with a H/o deafness of both ears since the age of 4 months following an attack of measles.H/o malaria at $61 / 2$ yrs when he was diagnosed with renal failure and hypertension. Regular dialysis was done. Underwent right renal transplantation at 7 years. H/o multiple blood transfusions given prior to surgery. This could be the probable reason for developing Hepatitis C infection. Patient had been using hearing aid till 4 years with irregular speech therapy Hearing tests with free field audiometry, oto acoustic emissions, BERA showed bilateral severe to profound Sensori neural hearing loss. The child on examination had a moderate build with adequate airway with stable vitals. Medical opinion taken, patient was taken with moderate high risk in view of pediatric age,renal transplantation with altered renal status, Hepatitis C infection.

\section{Right ear cochlear implant surgery was planned.}

During pre-anaesthetic assessment, medical illness was ruled out and a rapport with the child was established. The basic surgical approach consisted of a postaural incision, creation of an implant bed over mastoid and insertion of electrode after securing haemostasis. The anaesthetic protocol involved a thorough assessment of general condition of the child with special reference to any congenital anomaly. General anaesthesia was administered. Premedication included Inj Glycopyrrolate $4 \mathrm{mcg} /$ $\mathrm{kg}$, inj. Ondansetron $0.1 \mathrm{mg} / \mathrm{kg}$, inj. Fentanyl citrate $1 \mathrm{mcg} / \mathrm{kg}$. Monitoring included electrocardiogram (ECG), pulse oximetry, end tidal carbon-di-oxide and Non-Invasive Blood Pressure (NIBP). Induction was done with Inj Thiopentone sodium 5MG/ KG, Inj Succinyl choline 2MG/KG. Endotracheal intubation done with ET no 5, cuffed portextube. Patient was maintained on $\mathrm{O}_{2}$ $+\mathrm{N}_{2} \mathrm{O}(1: 2$ ratio) +SEVOFLURANE MAC 1 and on SIMV mode of ventilation.

Inj fentanyl was repeated on as required basis. The maintenance fluid consisted of N/5 saline in 5\% dextrose. Electro diathermy was switched off, before the cochlear device was implanted on the patient. Patients were allowed to breathe spontaneously after the effect of suxamethonium wore off, however inj Atracurium was given whenever nerve stimulators were not used to locate the facial nerve. Air warming blanket device was used for prevention of hypothermia. Inj ondansetron $0.1 \mathrm{mg} / \mathrm{kg}$ was added in the drip just prior to skin closure .At the conclusion of surgery, inhalational agents were terminated patient reversed with inj.glcopyrrolate 8 $\mathrm{mcg} / \mathrm{kg}$ and inj neostigmine $0.05 \mathrm{mg} / \mathrm{kg}$. Extubation done when patient is fully awake, with adequate tone and power.

Postoperative pain relief was initially provided with fentanyl $1 \mu \mathrm{g} / \mathrm{kg}$ IV and was later supplemented with syrup ibugesic (ibuprofen $10 \mathrm{mg} / \mathrm{kg}$ ). Patient was observed in the Intensive Care Unit (ICU) for $48 \mathrm{hrs,} \mathrm{for} \mathrm{any} \mathrm{complication} \mathrm{related} \mathrm{to} \mathrm{surgery}$ and anaesthesia. There were no intra-operative haemodynamic or any other adverse events requiring intervention. The average duration of operation was 260 minutes. Patient was shifted to the recovery ward for observation and shifted to the wards after 24 hours. Patient was discharged after 15 days.

\section{Discussion}

A large number of children presenting for cochlear implant surgery have deafness of unknown origin and no family history [3]. All the cases in the present series had deafness of unknown etiology. However, a significant number are of genetic origin and of autosomal recessive inheritance. The syndromes associated with hearing loss are usually hereditary and in most cases the genetic defect affects the development of both the ear and related systems. The various syndromes are designated as Usher, Pendred, Waardenburg, Treacher Collins, KlippelFeil, Jervel and Lange-Neilsen, Refsum, AlbersSchonberg, Cockayne and trisomy 13 and 18 syndromes. These syndromes are not only important from anaesthetic point of view but also are associated with various types of dysplasia of temporal bones and cochlea named after Michel, Mondini, Scheibe and the BingSiebenmann [4]. These dysplastic changes may necessitate change in the technique of placing the implant in the cochlea. Approximately $50 \%$ of the cases have acquired hearing loss mostly because of perinatal infections with TORCH group of organisms. Preoperative assessment also includes certain psychological tests to exclude those patients who may have organic brain dysfunction, mental retardation and undetected psychosis. It is also important to rule out retro-cochlear hearing loss and to be sure that the child has a communication handicap not amenable to hearing aids. If the child has severe to profound hearing loss and is likely to need the implant, further preparation requires objective assessment of hearing, plain X-rays of skull and a high resolution computerized tomographic (HRCT) scan of the temporal bone. An objective assessment of hearing (steady state evoked potential, auditory brainstem evoked potential and electrocochleography) is needed when the child is under five years of age. HRCT scan of temporal bone is done to see the basal turn of cochlea, its patency and any abnormal ossification within the cochlea secondary to meningitis. It also gives an indication about degree of mastoid pneumatization, presence of fluid in middle ear and any congenital inner ear abnormality. All these factors have a bearing on insertion of electrode array. If cochlea is filled with fibrous tissue following labyrinthitis, then it is necessary to carry out an MRI examination under anaesthesia [5]. 
If the child has impaired vision because of congenital cataracts as associated with Usher Syndrome, it should be corrected so that maximum help can be obtained with lip-reading during post-surgical auditory rehabilitation. Children with congenital deafness have a variety of syndromal illnesses, each of them having specific anaesthetic significance. Abnormalities in facial appearance and therefore difficult airway may point at presence of Treacher Collins Syndrome whereas eye disorders could form a part of Usher syndrome. KlippelFiel anomaly is associated with fusion of the cervical vertebrae making the intubation of the trachea a difficult proposition. Alport syndrome is commonly associated with renal failure and endocrinal abnormalities, whereas goiter and metabolic disorders are features of Pendred syndrome. Children with congenital hearing loss may also have Jervell and Lange-Nielsen Syndrome [6]. This syndrome is usually associated with a history of syncopal attacks or fits and the condition often manifests as prolonged QT interval on the ECG leading to dangerous ventricular arrhythmias. Therefore, these patients could be treated with beta blockers prior to cochlear implant surgery. There has been a report of a child suffering from this syndrome who became hypoglycaemic during preoperative period [7] whereas in another report the child was kept under cardiac monitor for 48 hours as an extreme precautionary measure. This child experienced a syncopal episode requiring placement of an automatic pacemaker and defibrillator subsequently, during auditory rehabilitation [8]. Parental presence is highly desirable during induction of anaesthesia since lack of communication is a big hurdle in establishing rapport. These deaf-mute children, similar to a normal child, are able to recognize strange environment as being alien and have fear of separation, pain and physical harm. Parental presence reduces separation anxiety significantly and has been shown to decrease the number of upset children during induction [9].Initially oral midazolam was used as a premedicant, subsequently we changed our approach to induce the child in mother's lap with $3 \mathrm{mg} /$ $\mathrm{kg}$ of thiopentone, whenever possible. Gaseous or intravenous induction, both are equally suitable. Choice of anaesthetic drugs is guided by the concern for post-operative nausea and vomiting and routine monitors are employed intraoperatively. Children having acute middle ear infection or meningitis are not posted for surgery. However, if the preoperative assessment reveals a temperature greater than $38^{\circ} \mathrm{C}$, due to an upper respiratory tract infection, not only does this predispose to a post operative chest infection, but the elevated temperature can render a child susceptible to poor temperature control intraoperatively. Such cases should be deferred. Usually, hypothermia is not a problem as the child is well covered with drapes. Active heating with forced warm air can be used if there is any concern pertaining to poor temperature control because of low ambient temperature or any other reason. Blood loss is usually minimal but can be substantial if care is not taken in presence of a large mastoid emissary vein. It can be visualized on X-ray or CT scan preoperatively. In order to reduce bleeding into the operating field, mild hypotension and mild hypocapnia can be maintained. During the conduct of surgery it is essential to identify the facial nerve and it is often done with the help of a nerve stimulator. This precludes use of muscle relaxants and therefore necessitates use of an appropriate technique. It is not worthy that since a cochlear implant is an electric device; a discharge of static electricity can damage the electrical component of the cochlear implant device and/or corrupt the programme in the speech processor. Hence, eletrosurgical instruments should not be used at all once the cochlear implant is in place. Haemostasis may be less than perfect on account of inability to use cautery, however it is not significant. At the conclusion of the operation, BERA testing of the electrode array is used or electrically evoked stapedius reflexes are evaluated to ensure proper function of the receiver stimulator, electrode array and to check the integrity of the implant. During these situations, the concentration of inhalation agents must be kept at the minimal level and no significant fluctuations in blood carbon-di-oxide levels should be allowed to occur. However, one study suggested that with the use of the right intravenous anaesthetics, the data pertaining to electrically evoked stapedius reflex obtained intraoperatively, can be used to prove immediately the functioning of the device, integrity of the peripheral auditory pathways and to predict comfort levels [10]. A post operative $\mathrm{X}$-ray of the position of the array within the cochlea is also taken which serves both as record of the position of the electrode and to assist in making.

\section{Conclusion}

An adequate pre operative preparation, selecting appropriate anesthesia and careful pre and post operative monitoring goes a long way in the successful management of such rare syndromic case of cochlear implantation in a patient with renal and hepatic impairment and on long term immuosupressive therapy. Cochlear implantation is a challenging specialized surgery and anaesthesiologist's awareness of the pitfalls and resourcefulness in dealing with communication impaired, paediatric age group makes the task satisfying. Being an extremely expensive prosthesis the expectations from the surgery and anaesthesia outcome are naturally very high, and all care should be taken to provide the best possible results.

\section{References}

1. Ashish Chakrabarty, VK Tarneja, Surg Vice Adm VK Singh, AVSM, VSM , Brig PK Roy, Col AK Bhargava, DK Sreevastava. Cochlear Implant : Anaesthesia Challenges. MJAFI. 2004;60(4).

2. Oxford Textbook of Clinical Nephrology ( 4 ed.)Edited by Neil N. Turner, Norbert Lameire, David J. Goldsmith, Christopher G. Winearls,Jonathan Himmelfarb, Giuseppe Remuzzi, and William G. Bennet, Mark E. de Broe, Jeremy R. Chapman,Adrian Covic, Vivekanad Jha, Neil Sheerin, Robert Unwin, and Adrian Woolf.

3. O'Sullivan PG, Elli SM, Pyman BC, Clark GM. The relationship between aetiology of hearing loss and outcome following cochlear implantation in a paediatric population. Proceedings of the XVI World Congress of Otorhinolaryngology, Head and Neck Surgery, Sydney, Australia. 1997.

4. Clark GM, Pyman BC. Preoperative medical evaluation. In: Clark GM, Cowan RSC, Dowell RC, editors. Cochlear implantation for infants and children, Singular Publishing Group, San Diego. 1997:71-110.

5. Clark GM, Cohen NL. Shepherd RK. Surgical and safety considerations of multi-channel cochlear implants in children. Ear and Hearing. 1991;(supplement 12):15-24. 
6. Clark GM, Pyman BC, Webb RL. Surgery. In: Clark GM, Cowan RSC, Dowell RC, editors. Cochlear implantation for infants and children, Singular Publishing Group, San Diego. 1997:111-124.

7. Baines DB, Murrell D. Preoperative hypoglycaemia, propranolol and the Jervell and Lange-Nielsen syndrome. Paediatr Anaesth. 1999;9(2):156-158.

8. Green JD, Schuh MJ, Maddern BR, Haymond J, Helffrich RA. Cochlear implantation in Jervell and Lange-Nielsen syndrome. Ann Otol Rhinol Laryngol. 2000;185:27-28.
9. Hannallah RS, Rosales JK. Experiments with parent's presence during induction in children. Can AnaesSoc J. 1983;30:286.

10. Gnadeberg D, Battmer RD, Lullwitz E, Laszig R, Dybus U, Lenarz T. Effect of anaesthesia on the intraoperative elicited stapedius reflex. Laryngorhinootologie. 1994;73(3):132-135. doi: 10.1055/s-2007997095 